\title{
CHARACTERIZATION OF METAL WORKING FLUIDS USING TRIBOLOGICAL TESTING METHODS
}

\author{
N. Ostrowicki ${ }^{1 *}$, J. Markert ${ }^{1}$, N. Hanenkamp ${ }^{1}$ \\ ${ }^{1}$ University Erlangen-Nuremberg, Institute for Resource and Energy Efficient Production Systems, Dr.-Mack-Str. 81, \\ 90762 Fürth, Germany \\ *Corresponding author; e-mail: nicolai.ostrowicki@fau.de
}

\begin{abstract}
The objective of this paper is to determine whether it is possible to compare the lubricating properties of different Metal working fluids (MWF) for a defined cutting application using easily reproducible tribological tests. The idea is that this will eventually allow users of MWF to select the most suitable MWF for a specific application without the need to run expensive and time-consuming tests on a machine tool being unavailable for production during that time. The test method chosen is the Pin-on-Disc (PoD) test, as there has been extensive research and an easy setup can be acquired inexpensively, making it more available and attractive for potential users. The PoD-tests were done with two groups of MWF, those for wet machining and those for minimum quantity lubrication (MQL). Additionally, the viscosity of the MQLMWF has been measured using a capillary viscometer. The evaluation of the wear on the pins and discs with different measuring devices shows consistent and promising results for the comparison of MQLMWF, while the MWF for wet machining display only limited comparability with the PoD-setup used.
\end{abstract}

Keywords:

Metal working fluids; Minimum quantity lubrication; Pin-on-Disc; Tribology

\section{INTRODUCTION}

Metal working fluids (MWF) are essential factors influencing the result and the economic efficiency of machining processes. They can have an impact on the tool life, the surface quality and the component edge zone [Denkena 2011, Gross 2019]. To select a suitable MWF, the user has so far only had access to the relevant data sheets and advice from the MWF manufacturers. Therefore, the decision is often preceded by expensive and timeconsuming machining trials with different MWF in order to compare them with each other and test their suitability. For this purpose, the machine has to be cleaned and refilled several times, and a lot of material and tools are needed. Consequently, the challenge and ultimate goal is to select a high-performance MWF fitting for the machining task without having to carry out the aforementioned tests. Consequently, an alternative method for comparing and selecting MWF is needed. In this paper the approach is based on the main functions of MWF, lubrication and cooling. The first aim is therefore to determine the lubrication performance with the aid of tribological measuring equipment in order to be able to compare different MWF with each other.

\section{STATE OF THE ART}

Tribological tests are divided into six categories [Czichos 2015; Möller 2002] depending on how close to or abstracted from the working conditions they are. Pin-on-Disc and similar tribometers, such as modified Pin-on-Disc, Pin-onRing or Cylinder-on-Disc, mostly belong in category $\mathrm{VI}$ since they work with abstract test geometries. This may lead to less transferability and the possibility of distorting the results due to the differences in the stress collective. However, there are also significant upsides of abstracted experiments, such as the better control of test parameters and thus the smaller variation of results. Another important advantage is that the cost and time efforts are often small compared to tests under real working conditions. [Gesellschaft für Tribologie e.V. 2002; Czichos 2015]

PoD tribometers have been studied and developed extensively [Olsson 1989; Hedenqvist 1991]. Olsson and Hedenqvist were the first ones to introduce an open tribometer as opposed to a closed one. "Open" means that the pin, sphere or cylinder always glides over a new surface, whereas on a closed tribometer it glides over the same surface repeatedly [Claudin 2008; Bonnet 2008; Rech 2009; Claudin 2010]. The purpose of this is to simulate wear more accurately. A continuously new surface is usually achieved by mounting the tribometer setup to a lathe and either having a cutting tool precede the pin [Olsson 1989] or by having the pin slide in a spiraling path across a cylinder [Hedenqvist 1991]. The main problem with these early open tribometers was that they were not able to achieve sufficient contact pressures that would be similar to those at the cutting zone between the tool and workpiece 
[Zemzemi 2007; Bonnet 2008]. Later research aimed to apply contact pressures of 1 to $3 \mathrm{GPa}$ and did so by further developing the test setups and utilizing pneumatic jacks [Zemzemi 2007; Zemzemi 2008].

PoD tribometers were used to develop a better understanding of wear and friction phenomena, to examine the coefficient of friction (COF), the heat flux and to test the durability of tool coatings. Numerical models were developed as well. Important parameters for these experiments are the contact pressure, the gliding velocity and the temperature. Especially notable for this is the work of Rech, Zemzemi, Claudin and Grzesik [Ben Abdelali 2012; Bonnet 2008; Claudin 2010; Claudin 2008; Rech 2013; Rech 2009; Zemzemi 2009; Zemzemi 2008; Zemzemi 2007]. More recently, lubricating media were introduced to the experiments that were formerly mostly run under dry conditions.

[Meier 2017] and [Sterle 2019] recently compared different tribometer setups (open and closed) which showed slight differences in the COF for some testing conditions depending on the type of tribometer. [Khan 2019] successfully compared two newly developed lubricants using a setup very similar to the one in this paper. The focus, however, was the development of lubricants whereas this paper focuses on the application and use of MWF.

\section{EXPERIMENTAL SETUP}

\subsection{Capillary viscometer}

The capillary viscometer measures the kinematic viscosity of fluids. In order to do so, the viscometer is emerged in a temperature-controlled water bath. The setup for the temperature control uses equipment by Julabo $\mathrm{GmbH}$. Additionally, a Pt100 sensor monitors the temperature. To operate the viscometer a safety pipette filler is used. The capillary viscometer is chosen according to the viscosity range. In this case most measurements were conducted with the Ubbelohde-viscometer supplemented with the Cannon-Fenske Opaque viscometer (CFO) for a particularly low viscosity. The setup is shown in Fig. 1.

The capillary viscometers are used according to the instructions specific to each viscometer. Through negative pressure and overpressure, the fluid is moved to the starting position. It is then released and flows through the capillary. In doing so the measuring bulb is filled or emptied depending on the viscometer used.

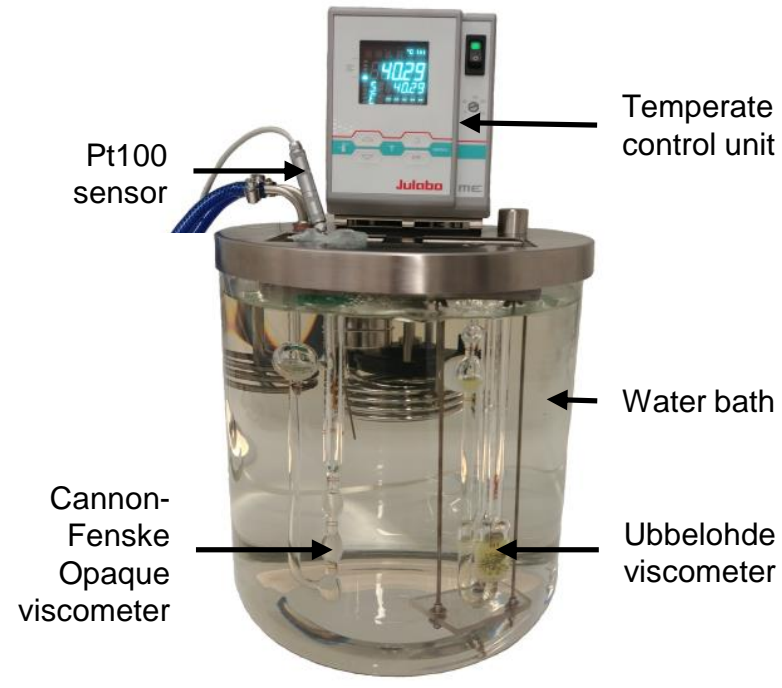

Fig. 1: Capillary viscometer setup.
The measuring bulb generally has two lines marking the start and end of the measuring time when crossed by the fluid. This time is manually measured using a stopwatch and then multiplied by the specific viscometer-constant, giving the kinematic viscosity.

\subsection{Pin-on-Disc tribometer}

The PoD tribometer used is an in-house construction, designed for gliding velocities between 0.05 and $5 \mathrm{~m} / \mathrm{s}$, surface pressures between 0.1 and $20 \mathrm{~N} / \mathrm{mm}^{2}$. The pins usually tested have the dimension $6-8 \mathrm{~mm} \times 4 \mathrm{~mm} \times 4 \mathrm{~mm}$ with a flat contact surface. A schematic description is shown in Fig. 2.

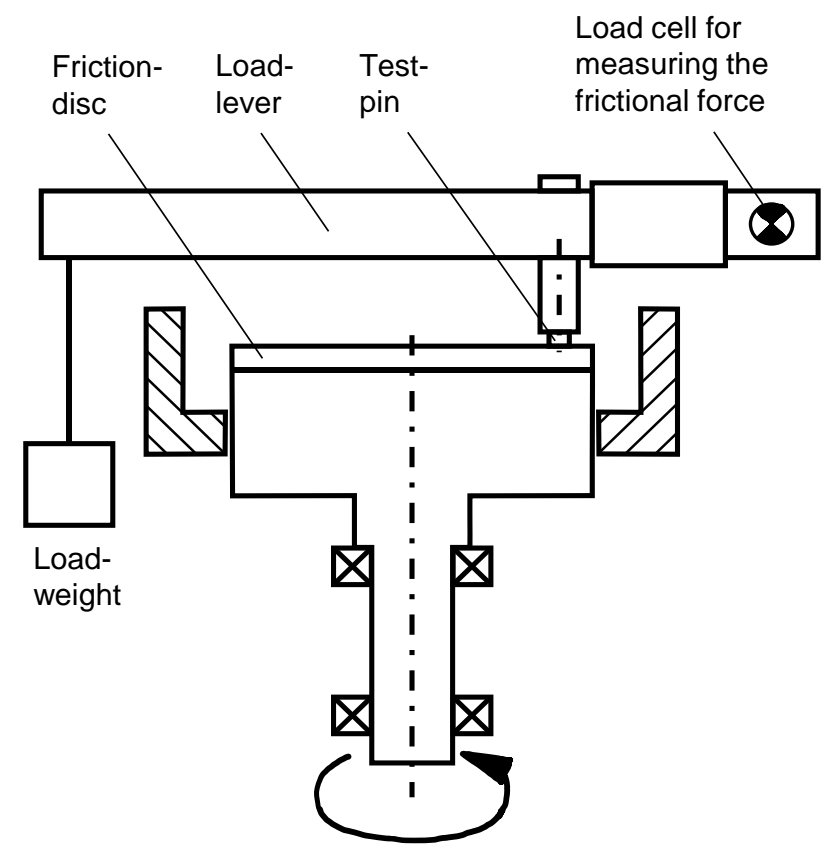

Fig. 2: Schematic description of the used Pin-on-Disc tribometer.

To increase the contact pressure to about $2 \mathrm{GPa}$, pins with a rounded surface ( $4 \mathrm{~mm}$ radius) are constructed and manufactured from hard metal. The discs are customized to fit the tribometer. Both, pins and discs, are labeled to ensure a reliable assignment to the experiments. A new pin is used for every test, but three tests can be run on each side of the disc, leaving an inner, middle, and outer track. The true-to-scale isometric view of both, a test-pin and a friction-disc, is shown in Fig. 3.

To compensate for the different radii of the tracks, the rotation frequency is adjusted accordingly. During the test, a load cell measures the frictional force, and an inductive displacement transducer tracks the wear. The length-of-run is controlled by calculating and tracking the running time using the sliding velocity.

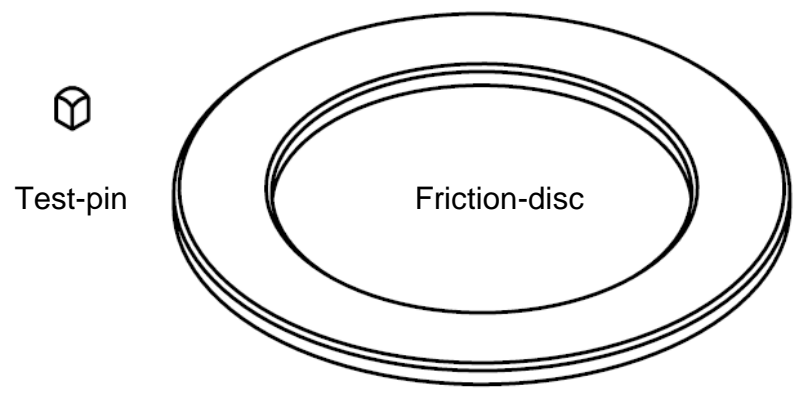

Fig. 3: Isometric view of test-pin and friction-disc. 
The method of applying the MWF to the contact area during the test is essential. The non-water-miscible (nwm) MWF are applied using a pipette in three-minute intervals near the contact area. The water-miscible (wm) MWF are used in wet machining, meaning the contact area should be fully emerged in MWF at all times.

However, the turning motion of the tribometer causes the MWF to collect at the sides of the trough. As an alternative a drip system is used to facilitate a high frequency of MWF droplets reaching the contact area. The entire setup is shown in Fig. 4.

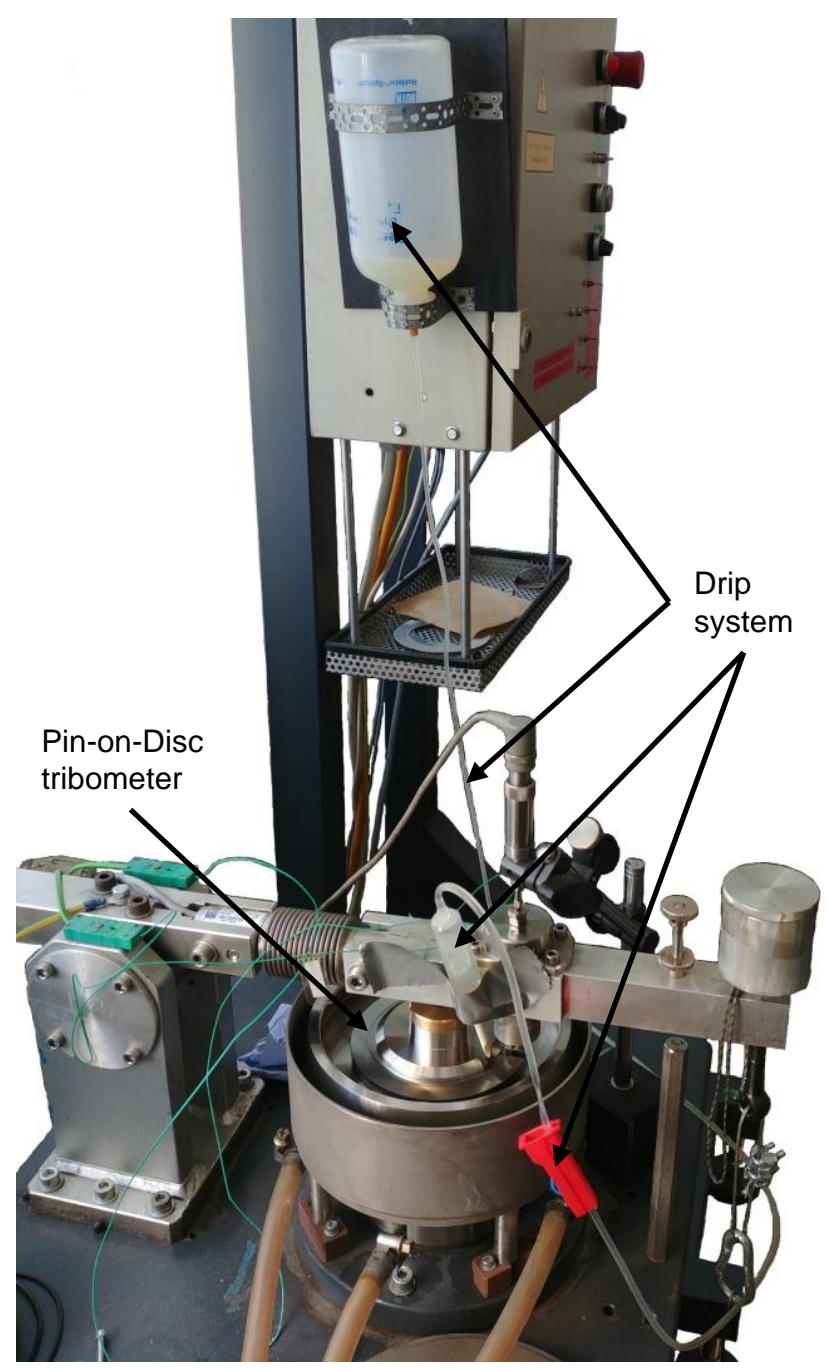

Fig. 4: Pin-on-Disc tribometer with drip system.

\subsection{Metal working fluids}

Four MWF for both categories have been selected. Additionally, tests under dry conditions and with water are conducted as references. Tab. 1 lists the nwm MWF, while Tab. 2 shows the wm MWF.

Tab. 1: Nwm MWF used in the experiments.

\begin{tabular}{|l|l|}
\hline Non-water-miscible MWF & Base \\
\hline NWM 1 & Ester oil \\
\hline NWM 2 & Fatty acid esters \\
\hline NWM 3 & Synthetic esters, bio oil \\
\hline NWM 4 & Unknown \\
\hline
\end{tabular}

Tab. 2: Wm MWF used in the experiments.

\begin{tabular}{|l|l|}
\hline Water-miscible MWF & Type \\
\hline WM 1 & Emulsion \\
\hline WM 2 & Emulsion \\
\hline WM 3 & Emulsion \\
\hline WM 4 & Full-synthetic solution \\
\hline
\end{tabular}

For each group MWF from four different manufacturers were chosen. The MWF are not further specified to prevent possible negative ramifications for the manufacturers. NWM 4 was given to the REP by a manufacturer of MQL systems to be used with their system without any further information. The "unknown" fluid was therefore included, because in reality the customer might not always know all the details either.

Each MWF is tested three times under the same conditions, but once on each track (inner, middle, outer). The wm MWF are tested with a concentration of $8 \%$, with WM 2 and WM 3 additionally being tested at $3 \%$ and $13 \%$. Due to limited materials and machine time not all wm MWF could be tested at three concentrations. Every combination of MWF and concentration was tested three times.

\section{TEST EXECUTION}

\subsection{Capillary viscometer}

The capillary viscometer was provided for a test capacity of three fluids at three temperatures. Therefore, three of the nwm MWF have been chosen and their viscosity is measured at $20^{\circ} \mathrm{C}, 40^{\circ} \mathrm{C}$ and $60^{\circ} \mathrm{C}$. This allows for a better understanding of the relationship between viscosity and temperature. For each viscosity the measurements are repeated five times and the average was taken.

\subsection{Pin-on-Disc tribometer}

In order to compare different MWF as many parameters as possible aside from the MWF should be fixed. Therefore, a specific cutting situation to be simulated in the PoD-tests is chosen: smooth longitudinal turning of $100 \mathrm{Cr} 6$ using a hard metal tool at a cutting velocity of $140 \mathrm{~m} / \mathrm{min}$ under wet machining and minimum quantity lubrication (MQL). Therefore, the same materials are used for the disc and the pin and the gliding velocity is set to $140 \mathrm{~m} / \mathrm{min}$. This simulates the speed at the tool flank face while the speed at the rake face would have to be simulated at about 70 m/min [Astakhov 2008; Bonnet 2008; Claudin 2008; Rech 2009]. The test length is set to $4000 \mathrm{~m}$.

Before the test execution the setup is cleaned to avoid any oil residue that could temper with the results. The disc and pin are fastened in their fixtures, their respective labelled numbers are recorded and the tribometer as well as the measuring software is prepared. The MWF is dripped onto the contact area and around the disc, so that the run is lubricated from start to finish since a dry start might alter the results. These preparations are redone before every test. The test is then started and timed. While the experiment is running the tracking software displays the coefficient of friction (COF) and the measurements from the inductive displacement transducer. This display is used to monitor the run and detect any inconsistencies or anomalies such as rattling or sudden spikes in the COF. Every experiment is repeated at least two more times. An anormal run can be redone a second time. 


\section{RESULTS}

\subsection{Analysis of the viscosity tests}

The time measurements from the tests multiplied by the specific viscometer-constant directly result in the kinematic viscosity. The viscosity, however, changes with different temperatures. This is relevant because the MWF usually heats up when getting to the contact zone between the tool and the workpiece. This is the reason for testing three different temperatures. The results are shown in Fig. 5.

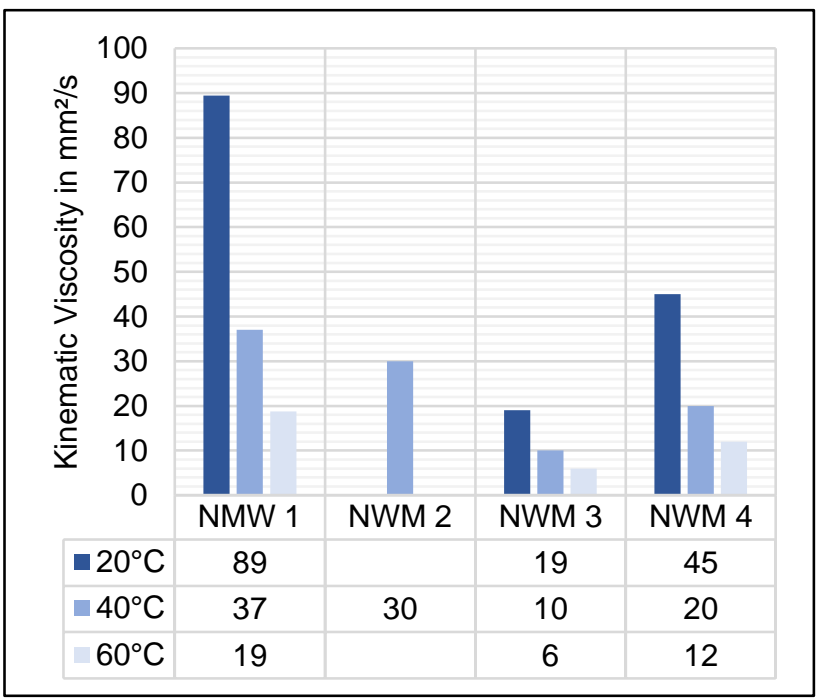

Fig. 5: Kinematic viscosity of the nwm MWF measured on the capillary viscometer (NWM 2 from product data sheet).

\subsection{Analysis of the Pin-on-Disc test results}

The frictional force is measured during the experiments through a load cell and then converted into the coefficient of friction (COF) factoring in the load-weight. As mentioned before there is also an inductive displacement transducer positioned on the load lever shown in Fig. 2. While the vibrations of the lever do not allow for an accurate measurement of the wear, the data from the transducer are a good indicator for any disturbances in the run, caused for example by swarf collecting on the disk. Both the COF and the displacement are monitored over the time of each experiment in graphs automatically produced by the software connected to the tribometer. The progression of both, the vibrations and COF, throughout the run were carefully analyzed. However, the results are not clear cut and discussing them would exceed the scope of this paper.

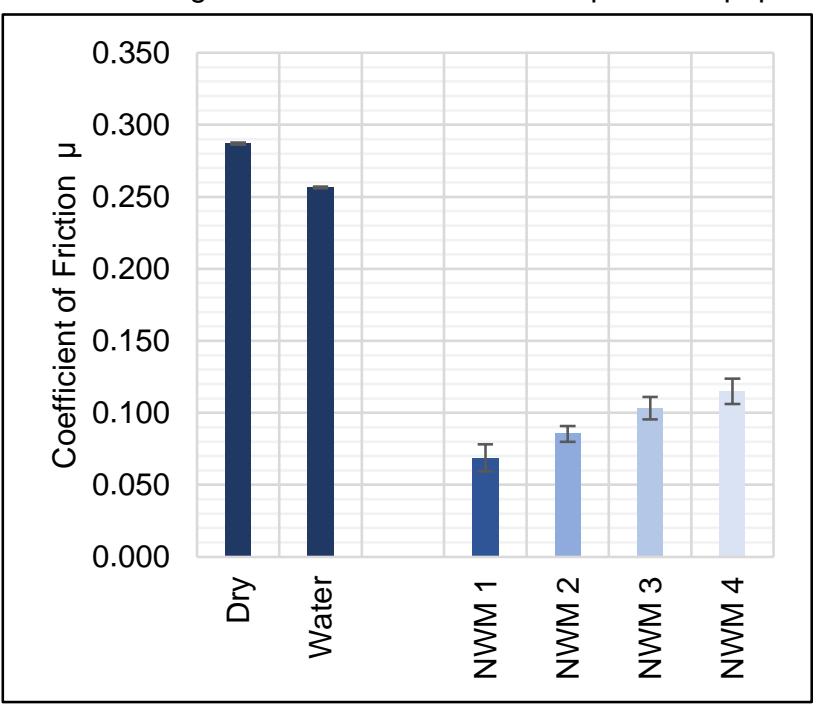

Fig. 6: Average coefficient of friction (nwm MWF).
For the quantitative analysis the average COF for each MWF (measurement interval 1s; averaged over all three runs of each set of test conditions) was calculated and the results are shown in Fig. 6 and Fig. 7.

Nwm MWF can be compared well using the average COF, as seen in Fig. 6. However, Fig. 7 shows that for the wm MWF there were no clear differences detected by the used test setup, even at different concentrations. Later measurements for example of the wear marks of the tests with on the pins also show significant standard deviations. This is the case for all other identified quantitative measurements as well. In conclusion, the test setup (as it was used in this paper) is not capable of comparing wm MWFs. Because of this, the rest of this chapter will focus on the comparison of nwm MWF.

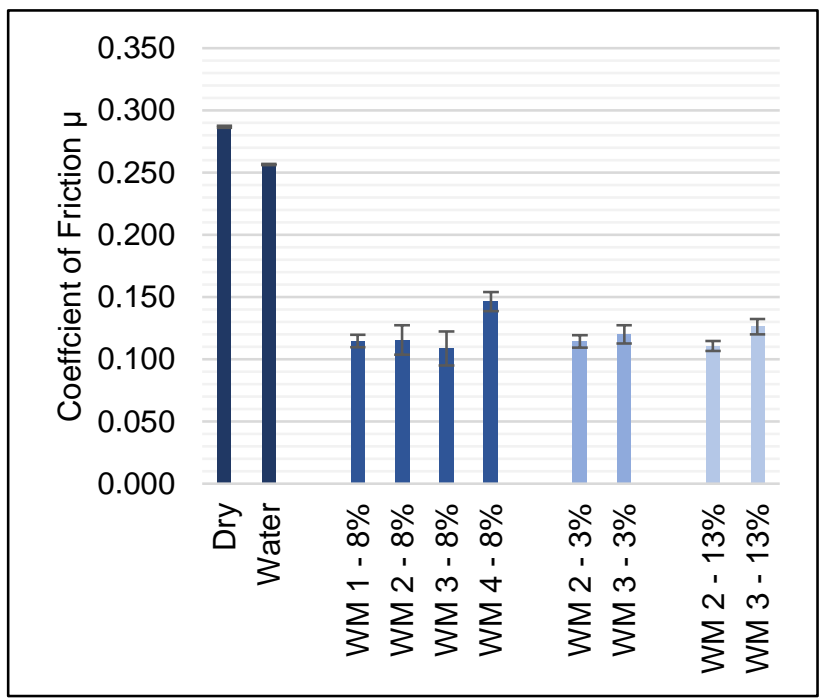

Fig. 7: Average coefficient of friction (wm MWF).

To get an accurate analysis of the wear itself, it is analyzed from a qualitative and quantitative perspective. In order to do so, different measuring devices are used. Furthermore, both, the pins and the marks left on the disks, are taken into consideration. The pins are analyzed with the digital microscope Keyence VHX 5000 at magnifications of up to 200. The software of the microscope can also be used to measure the wear on the pins as shown in Fig. 8.

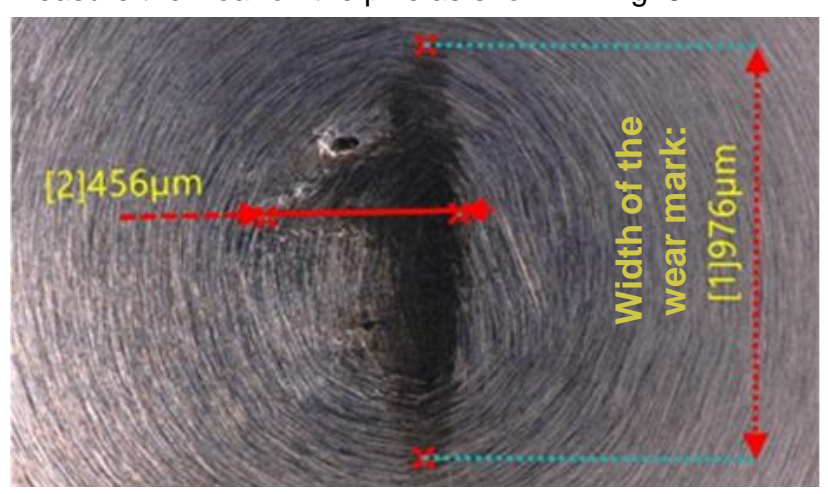

Fig. 8: Measurement of the wear on the pins.

The qualitative comparison of the nwm MWF shows only slight differences between NWM 1 and the others. The pin lubricated with NWM 1 visibly did not penetrate the disk as deeply. For the wm MWF no definite differences between MWF and/or concentrations are visible in the qualitative analysis. For the quantitative analysis only the width of the mark on the pin is considered. It needs to be mentioned at this point, that the marks on the lubricated pins appear to be discolorations most of the time as opposed to the clear 
abrasions on the dry tested pins (refer to Fig. 14 and Fig. 15). The width comparison results are shown in Fig. 9.

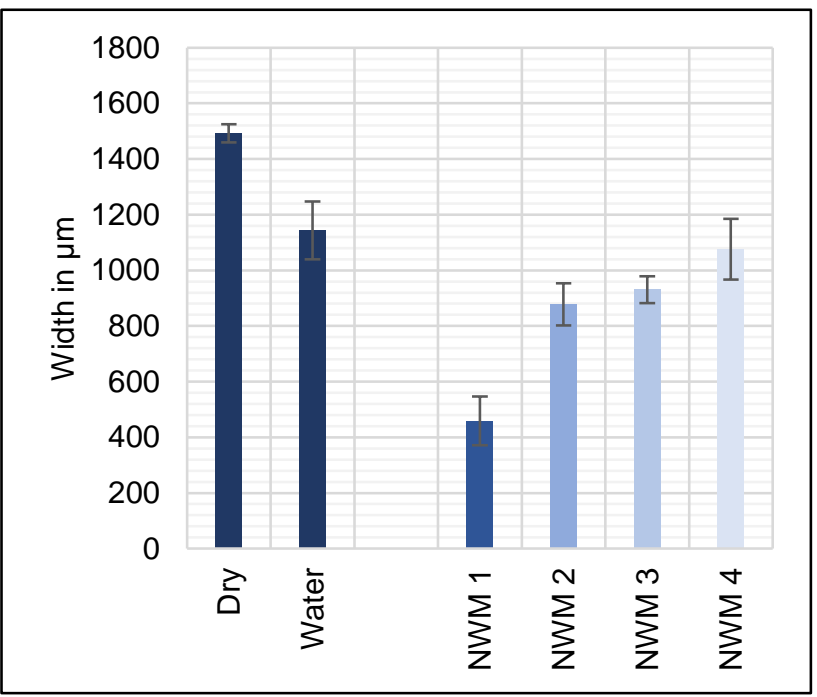

Fig. 9: Width of the wear marks on the pins (nwm MWF).

The wear on the discs appears as tracks that are measured at five points in $72^{\circ}$ intervals. Using the Keyence VHX 5000 the tracks are analyzed qualitatively and the average width of the tracks is recorded. The tracks showcase significant differences in surface, depth and especially consistency. There is, however, no clear pattern visible when analyzing these differences. The five frames of one such track are shown in Fig. 10 as an example. It is clear from Fig. 10 that the track width may vary greatly within a single track. For that reason the minimum and maximum width in each frame are measured and then the average for the three tracks of one MWF is calculated. This average width of the tracks from the experiments with nwm MWF is graphed in Fig. 11.
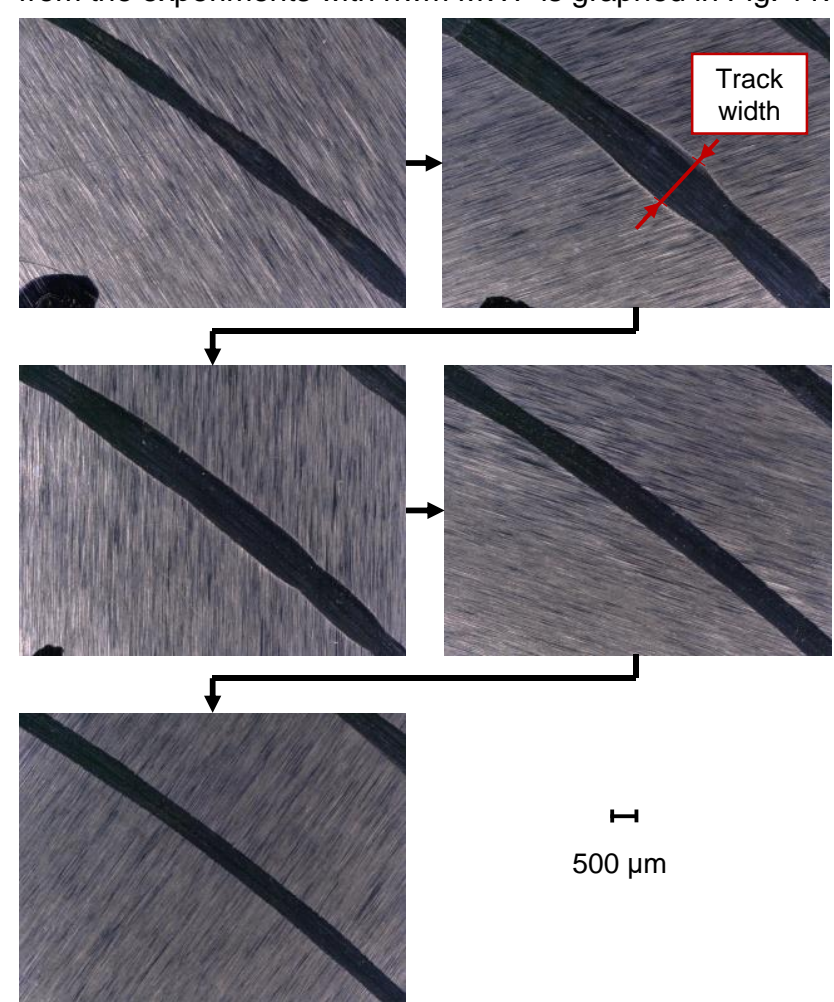

$500 \mu \mathrm{m}$

Fig. 10: Track as recorded by the Keyence VHX 5000 in five frames at $72^{\circ}$ intervals.

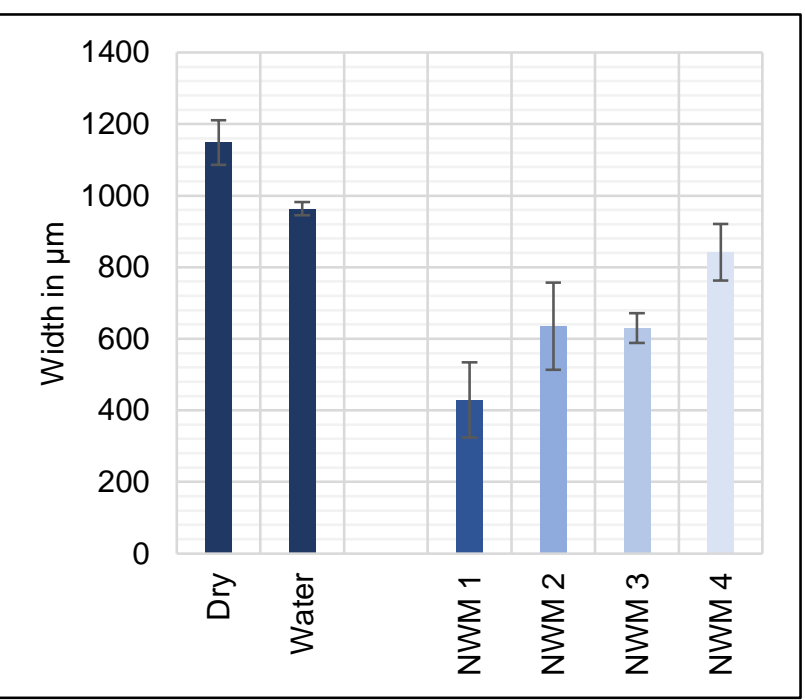

Fig. 11: Average track width (nwm MWF).

Besides the width, the profile of the tracks is measured as well. For this purpose the HOMMEL-ETAMIC T1000 wave device is used. Together with the software this device graphs the profile and can measure its maximum depth and height as well as the difference between the two. An example of a track profile and the measurement parameters is shown in Fig. 12. While all three parameters show the same pattern, it is most clearly distinguishable for the maximum depth, which is graphed in Fig. 13.

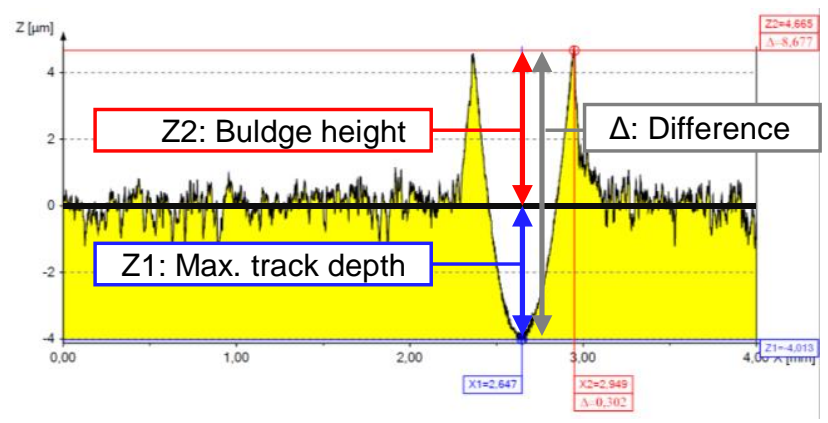

Fig. 12: Track profile as recorded by the HOMMELETAMIC T1000 wave.

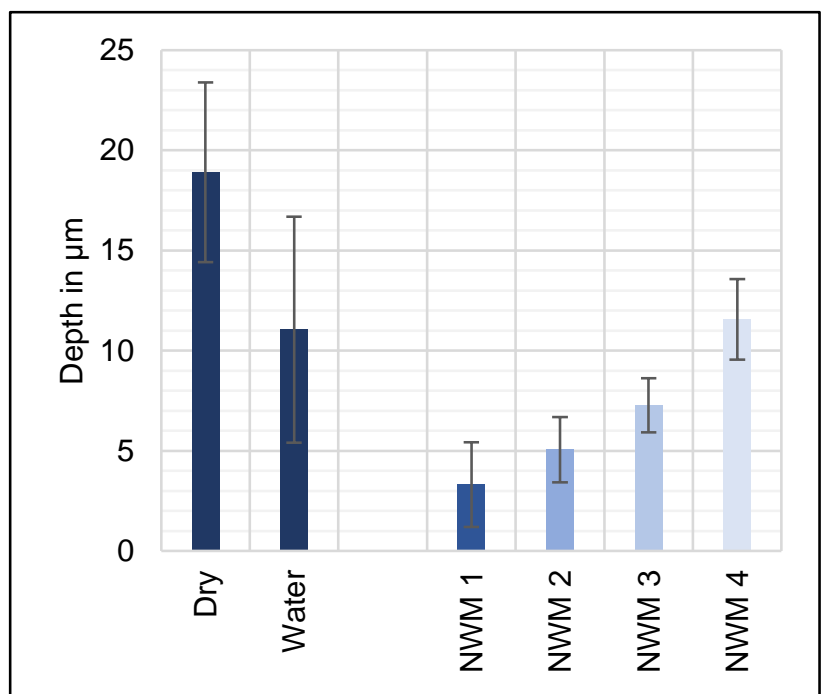

Fig. 13: Average maximum track depth (nwm MWF). 


\section{INTERPRETATION OF THE RESULTS}

\subsection{Comparison of the MWF}

As mentioned earlier both kinds of MWF were tested and examined in the same way. The wm MWF showed no clear indications regarding their lubricating properties. This may be the case because for this type of MWF the percentage of oil compared to water is rather low. As seen in the reference tests with pure water, it exhibits a COF similar to the dry run (refer to Fig. 6 and Fig. 7). In conclusion the lubricating abilities are mostly dependend on the oil within the MWF. Since there is comparatively little oil in wm MWF, the differences between them in regards to their lubricating properties are smaller and harder to measure. For this reason the graphs and detailed analysis of these tests were not further discussed in this paper.

For the nwm MWF, however, there were clear and coherent results. The analysis of the wear on the pins and discs for the tests with nwm MWF shows the same results as the COF. NWM 1 clearly yields the best results, followed by NWM 2, NWM 3 and NWM 4 in that order. This order is confirmed in all parameters albeit that the difference between NWM 2 and NWM 3 is not as big as between the other MWF.

Comparing the order of the lubricating properties from best to worst (NWM $1 \rightarrow$ NWM $2 \rightarrow$ NWM $3 \rightarrow$ NWM 4 ) to the order of the kinematic viscosities from highest to lowest $($ NWM $1 \rightarrow$ NWM $2 \rightarrow$ NWM $4 \rightarrow$ NWM 3 ) reveals some relation between the two factors. A high viscosity generally correlates to higher lubricating properties. However, as seen with NWM 4 and NWM 3 this is not always true, suggesting that other factors such as additives may play an important role as well.

\subsection{Tribological aspects}

In tribology four wear mechanisms are differentiated: abrasion, adhesion, surface fatigue and tribochemical reactions. In reality, there is usually more than one mechanism acting at the same time [Czichos 2015]. An exact identification requires further analyses; however, it seems that surface fatigue and abrasion were the most prominent mechanisms in the tests. This correlates to the pin running over the same disk surface repeatedly under pressure. To give an example the wear for one of each of the runs dry, with water and with the four nmw MWF is shown in Fig. 14 and Fig. 15.

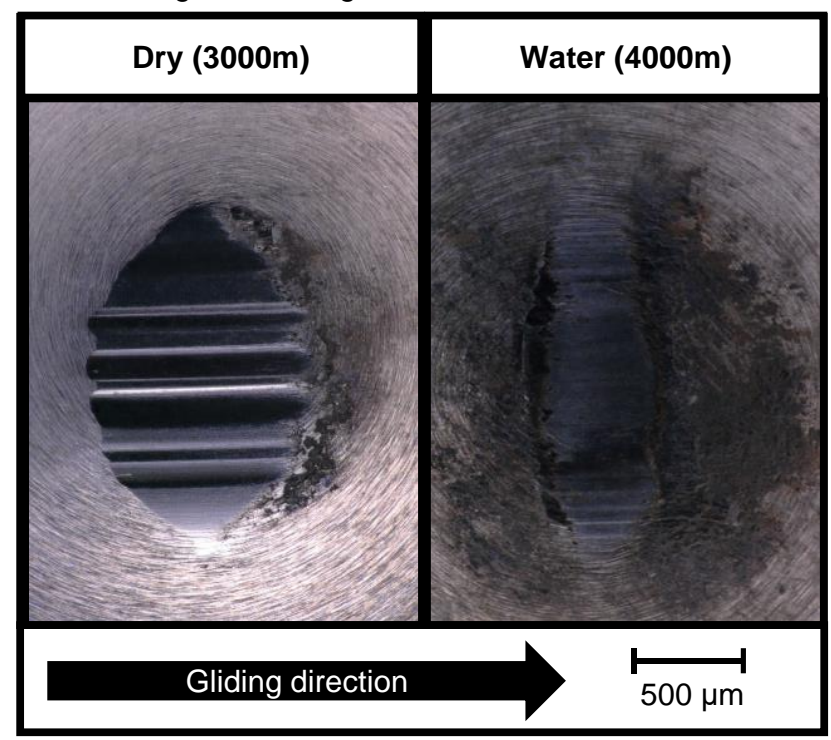

Fig. 14: Wear on the pins - dry and water (150x magnification).

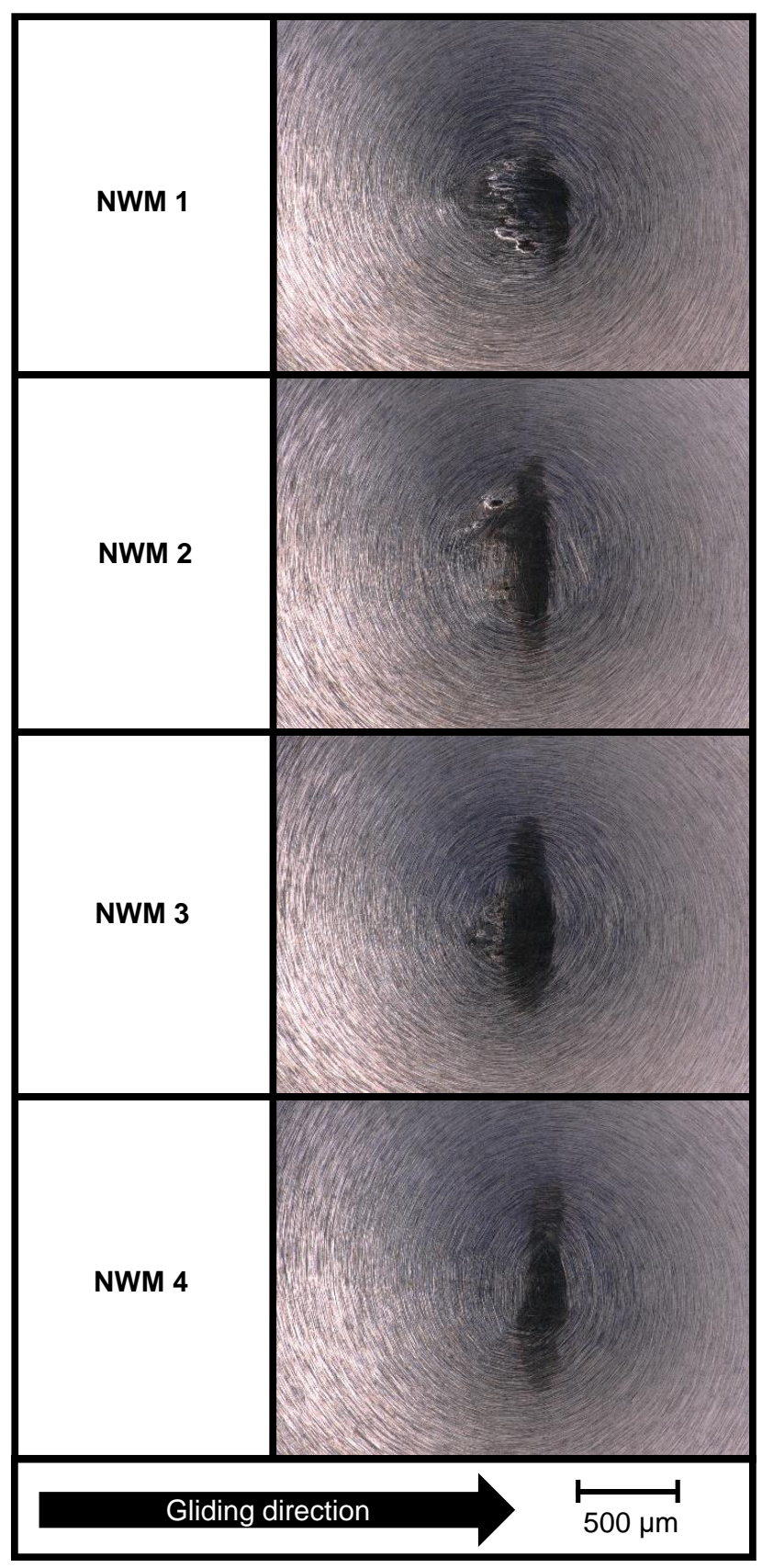

Fig. 15: Wear on the pins - nwm MWF (150x magnification).

Abrasion has four subcategories: microploughing, microcutting, microfatigue and microcracking [Zum Gahr 1987]. In newer literature microfatigue is sometimes exempt as it technically belongs to surface fatigue [Klocke 2018]. For the pin-on-disc tribometer microploughing and microcutting are especially interesting, because their ratio is determined by the ratio of maximum depth of the cut to the bulging of material on the sides of the cut [Zum Gahr 1987; Czichos 2015], as shown in Fig. 16. 


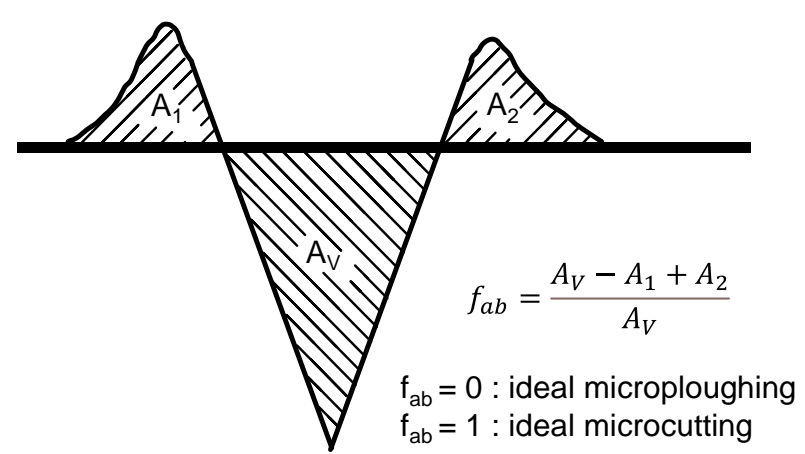

Fig. 16: Ratio of microploughing to microcutting [Zum Gahr 1987; Czichos 2015].

This is similar to how the profiles of the tracks on the disks present themselves. In Fig. 17 three different examples of ratios between track depth and bulge height are pictured, suggesting that cutting and ploughing are both present in different proportions for the PoD-experiments. However, due to the aforementioned inconsistencies in the tracks, no further conclusive analysis was possible.

It should also be mentioned that the high contact pressure and an alternating load are prone to causing surface fatigue, that is enhanced by the adhesion between the surfaces. This combination leads to material breaking off. As a results wear particles are formed and in turn cause further wear of the material.
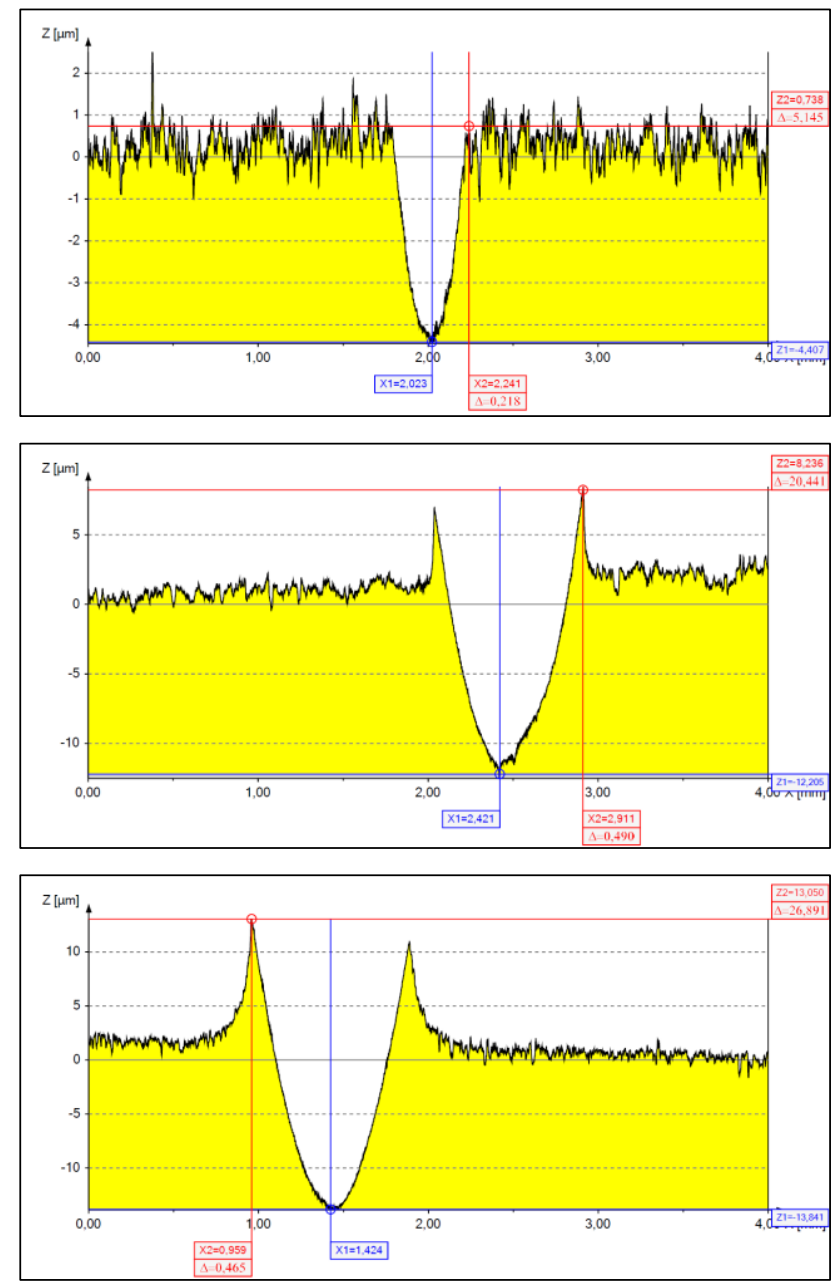

Fig. 17: Track profiles with different ratios of depth to bulging.

\section{SUMMARY}

The goal of this study was to determine the suitability of Pinon-Disc tests to compare MWF. The idea was that this would eventually enable the replacement of cutting tests when choosing a MWF for a specific application. It was determined in this paper, that the tests on the Pin-on-Disc tribometer were able to conclusively rank a selection of nonwater-miscible MWF according to their lubricating properties. The setup was, however, not suitable for comparing water-miscible MWF.

The initial ranking of the non-water-miscible MWF according to the in-process measurement of the COF was confirmed by quantifying the wear on the pins as well as the discs through multiple different measurements. While there seems to be some correlation between the kinematic viscosity and the lubricating abilities, since the oil with the highest viscosity achieved the best results regarding lubrication and wear, the lowest ranked two oils do not follow that correlation.

With regard to the water-miscible MWF a ranking was not possible among different concentrations for the same fluid, nor between different fluids at the same concentration. This may be due to water being the main component for this kind of MWF. The relatively low concentration of oil or another synthetic lubricant in the water causes the differences in lubrication to be so small, that the tribometer setup used was not able to compare the water-miscible MWF conclusively.

Further research is needed on this topic. It is suggested that the ranking for the non-water-miscible MWF is confirmed on an actual lathe using the chosen test conditions to verify whether or not the PoD test delivers the same results. Another possibility is to repeat the tests at different gliding velocities since literature suggests a strong influence of the velocity on the wear. Modifications to the setup should be done in order to more accurately simulate the application of lubricant regarding quantity and method, possibly reducing vibrations and increasing the accuracy of the tests to enable the comparison of water-miscible MWF. Lastly this paper should only be considered a starting point, as there are many more parameters, such as temperature and heat flux, and effects to be considered in order to gain more accurate results. In future setups a thermocouple could be added into the pin to monitor the temperature throughout the run.

There are certainly many more possibilities to refine the test conditions, however this paper specifically focuses on the industrial application of such tests. Consequently, the applicability, complexity and cost need to also be considered and should not eventually outweigh the benefits.

\section{ACKNOWLEDGMENTS}

This research activity was publicly funded by the European Social Fund (ESF) as part of the project "Qualification concept for sustainable cooling lubrication strategies".

\section{REFERENCES}

[Astakhov 2008] Astakhov, V. P. and Xiao, X. A. Methodology for practical cutting force evaluation based on the energy spent in the cutting system. Machining Science and Technology 12, Nr. 3, 2008, pp 325-347. https://doi.org/10.1080/10910340802306017

[Ben Abdelali 2012] Ben Abdelali, H., Claudin, C., Rech, J., Ben Salem, W., Kapsa, P. and Dogui, A. Experimental characterization of friction coefficient at the tool-chip- 
workpiece interface during dry cutting of AISI 1045. Wear 286-287, 2012, $\quad$ pp 108-115 https://doi.org/10.1016/j.wear.2011.05.030

[Bonnet 2008] Bonnet, C., Valiorgue, F., Rech, J., Claudin, C., Hamdi, H., Bergheau, J. M. and Gilles, P. Identification of a friction model-Application to the context of dry cutting of an AISI 316L austenitic stainless steel with a TiN coated carbide tool. International Journal of Machine Tools and Manufacture 48, Nr. 11, 2008, S. 1211-1223. https://doi.org/10.1016/j.jmachtools.2008.03.011

[Claudin 2010] Claudin, C., Mondelin, A., Rech, J. and Fromentin, G. Effects of a straight oil on friction at the toolworkmaterial interface in machining. International Journal of Machine Tools and Manufacture 50, Nr. 8, 2010, S. 681688. https://doi.org/10.1016/j.ijmachtools.2010.04.013

[Claudin 2008] Claudin, C., Rech, J. and Grzesik, W. Development of a new tribometer to identify the effects of coatings and lubricants during machining processes. In : 2nd International Conference «Innovative Cutting Processes \& Smart Machining Cluny ", Cluny, 22-23 October, 2008.

[Czichos 2015] Czichos, H., ed., Habig, K.-H., ed. Tribologie-Handbuch: Tribometrie, Tribomaterialien, Tribotechnik. 4., vollst. überarb. u. erw. Aufl. Wiesbaden: Springer Vieweg, 2015. https://doi.org/10.1007/978-38348-2236-9

[Denkena 2011] Denkena, B., Tönshoff, H.K., Spanen : Grundlagen, 3., bearb. u. erw. Aufl, Berlin, Springer, 2011, https://doi.org/10.1007/978-3-642-19772-7

[Gesellschaft für Tribologie e.V. 2002] Gesellschaft für Tribologie e.V. Arbeitsblatt 7 : TRIBOLOGIE - Definitionen, Begriffe, Prüfung, 2002. With assistance of Dr.-Ing. Ludger Deters, Dr.-Ing. Alfons Fischer, Erich Santner, Ulrich Stolz. Available online at: https://neu.gft-ev.de/wpcontent/uploads/2002_AB_7_Tribologie.pdf

[Gross 2019] Gross D., Bigelmaier M., Meier T., Amon S., Ostrowicki N., Hanenkamp N.: Investigation of the influence of lubricating oils on the turning of metallic materials with cryogenic minimum quantity lubrication, Procedia CIRP 80 2019, $\mathrm{S}$. 95-100, https://doi.org/10.1016/j.procir.2019.01.005

[Hedenqvist 1991] Hedenqvist, P. and Olsson, M. Sliding wear testing of coated cutting tool materials. Tribology International 24, Nr. 3, 1991, pp 143-150. https://doi.org/10.1016/0301-679X(91)90020-A

[Khan 2019] Khan, M. S., Sisodia, M. S., Gupta, S., Feroskhan, M., Kannan, S. and Krishnasamy, K. Measurement of tribological properties of $\mathrm{Cu}$ and $\mathrm{Ag}$ blended coconut oil nanofluids for metal cutting. Engineering Science and Technology, an International Journal 22, Nr. 6, 2019, pp 1187-1192. https://doi.org/10.1016/j.jestch.2019.04.005

[Klocke 18] Klocke, F. Fertigungsverfahren 1: Zerspanung mit geometrisch bestimmter Schneide. 9th ed. Berlin:
Springer Vieweg, 2018. https://doi.org/10.1007/978-3-66254207-1

[Meier 2017] Meier, L., Schaal, N. and Wegener, K. Inprocess Measurement of the Coefficient of Friction on Titanium. Procedia CIRP 58, 2017, pp 163-168. https://doi.org/10.1016/j.procir.2017.03.212

[Möller 2002] Möller, U. J. and Nassar, J. Schmierstoffe im Betrieb. 2nd ed. Berlin, Heidelberg: Springer Verlag, 2002. https://doi.org/10.1007/978-3-642-56379-9

[Olsson 1989] Olsson, M., Söderberg, S., Jacobson, S. and Hogmark, S. Simulation of cutting tool wear by a modified pin-on-disc test. International Journal of Machine Tools and Manufacture 29, Nr. 3, 1989, pp 377-390. https://doi.org/10.1016/0890-6955(89)90007-2

[Rech 2013] Rech, J., Arrazola, P. J., Claudin, C., Courbon, C., Pusavec, F. and Kopac, J. Characterisation of friction and heat partition coefficients at the tool-work material interface in cutting. CIRP Annals 62, Nr. 1, 2013, pp 79-82 . https://doi.org/10.1016/j.cirp.2013.03.099

[Rech 2009] Rech, J., Claudin, C. and D'Eramo, E. Identification of a friction model-Application to the context of dry cutting of an AISI 1045 annealed steel with a TiNcoated carbide tool. Tribology International 42, Nr. 5, 2009, pp 738-744. https://doi.org/10.1016/j.triboint.2008.10.007

[Sterle 19] Sterle, L., Pušavec, F. and Kalin, M. Determination of friction coefficient in cutting processes: comparison between open and closed tribometers. Procedia CIRP 82, 2019, pp 101-106. https://doi.org/10.1016/j.procir.2019.04.159

[Zemzemi 2008] Zemzemi, F., Bensalem, W., Rech, J., Dogui, A. and Kapsa, P. New tribometer designed for the characterisation of the friction properties at the tool/chip/workpiece interfaces in machining. Tribotest 14 , Nr. 1, 2008, pp 11-25. https://doi.org/10.1002/tt.50

[Zemzemi 2009] Zemzemi, F., Rech, J., Ben Salem, W., Dogui, A. and Kapsa, P. Identification of a friction model at tool/chip/workpiece interfaces in dry machining of AISI4142 treated steels. Journal of Materials Processing Technology 209, Nr. 8, 2009, pp 3978-3990. https://doi.org/10.1016/j.jmatprotec.2008.09.019

[Zemzemi 2007] Zemzemi, F., Rech, J., Salem, W. B., Dogui, A. and Kapsa, P. Development of a friction model for the tool-chip-workpiece interfaces during dry machining of AISI4142 steel with TiN coated carbide cutting tools. International Journal of Machining and Machinability of Materials 2, 3/4, 2007, pp 361-377. https://dx.doi.org/10.1504/IJMMM.2007.015472

[Zum Gahr 1987] Zum Gahr, K.-H. Microstructure and wear of materials. Amsterdam, New York: Elsevier, 1987. ISBN 9780080875743 